\title{
The effects of contemporary processes in maintaining the genetic structure of western song sparrows (Melospiza melodia)
}

\author{
CL Pruett ${ }^{1,2}$, P Arcese ${ }^{3}$, YL Chan ${ }^{4}$, AG Wilson ${ }^{3}$, MA Patten ${ }^{1,5}$, LF Keller ${ }^{6}$ and K Winker ${ }^{2}$ \\ ${ }^{1}$ Sutton Avian Research Center, University of Oklahoma, Bartlesville, OK, USA; ${ }^{2}$ University of Alaska Museum, Fairbanks, AK, USA; \\ ${ }^{3}$ Department of Forest Sciences, Centre for Applied Conservation Research, University of British Columbia, Vancouver, British Columbia, \\ Canada; ${ }^{4}$ Department of Biological Sciences, Stanford University, Stanford, CA, USA; ${ }^{5}$ Oklahoma Biological Survey and Department of \\ Zoology, University of Oklahoma, Norman, OK, USA and ' ${ }^{6}$ Zoologisches Museum, Universität Zürich, Zürich, Switzerland
}

\begin{abstract}
Historic events and contemporary processes work in concert to create and maintain geographically partitioned variation and are instrumental in the generation of biodiversity. We sought to gain a better understanding of how contemporary processes such as movement and isolation influence the genetic structure of widely distributed vagile species such as birds. Song sparrows (Melospiza melodia) in western North America provide a natural system for examining the genetics of populations that have different patterns of geographic isolation and migratory behavior. We examined the population genetics of 576 song sparrows from 23 populations using seven microsatellite loci to assess genetic differentiation among populations and to estimate the effects of drift and immigration (gene flow) on each population. Sedentary,
\end{abstract}

isolated populations were characterized by low levels of immigration and high levels of genetic drift, whereas those populations less isolated displayed signals of high gene flow and little differentiation from other populations. Contemporary dispersal rates from migratory populations, estimated by assignment test, were higher and occurred over larger distances than dispersal from sedentary populations but were also probably too low to counter the effects of drift in most populations. We suggest that geographic isolation and limited gene flow facilitated by migratory behavior are responsible for maintaining observed levels of differentiation among Pacific coastal song sparrow populations.

Heredity (2008) 101, 67-74; doi:10.1038/hdy.2008.31; published online 7 May 2008

Keywords: dispersal; distributional patterns; geographic isolation; microsatellites; Pacific coast; song sparrow

\section{Introduction}

Genetic variation within species provides the raw material for speciation, but many questions remain about the traits of organisms and the environment that facilitate biological diversification, including the role of historic and current processes such as vicariance and gene flow (Coyne and Orr, 2004). In vagile species, such as birds, it is often not known how genetic differentiation between populations is maintained in the absence of barriers to dispersal, particularly among migrants (Paradis et al., 1998; Arguedas and Parker, 2000). Here, we ask how migratory behavior and the distribution of song sparrow populations influences genetic structure along the Pacific coast of western North America where this species occurs in sedentary and partially migratory populations (Table 1; Arcese et al., 2002).

In a partially migratory population, some members of a population perform seasonal longer-distance movements, while other individuals remain in an area

Correspondence: Dr CL Pruett, Sutton Avian Research Center, University of Oklahoma, PO Box 2007, Bartlesville, OK, 74005-2007, USA.

E-mail: cpruett@ou.edu

Received 5 September 2007; revised 4 March 2008; accepted 26 March 2008; published online 7 May 2008 throughout the year. In sedentary populations, most or all adults remain on or near their breeding territories year-round (Arcese, 1989; Wilson and Arcese, 2008). This provides a unique system for comparing the genetic structure and gene flow among populations that exhibit differing migratory propensities. We can examine movement from sedentary into other sedentary populations, sedentary into migratory populations, migratory into sedentary and migratory into other migratory populations. We expect a genetic signal of low immigration and high drift among sedentary populations, but the opposite pattern of high immigration rates and low drift among migratory populations should exist, if migration facilitates dispersal.

Previous work on song sparrows suggests that historic links among populations have shaped population genetic structure, but to different degrees. Analyses of mitochondrial (mt) DNA markers revealed little genetic structure across much of North America but did suggest that song sparrows expanded postglacially into much of their current distribution (Hare and Shields, 1992; Zink and Dittmann, 1993; Fry and Zink, 1998). More recent studies using microsatellite markers report modest to marked population differentiation as a result of sequential founding events in Alaska (Pruett and Winker, 2005) and microgeographic effects in California (Chan and 
Table 1 Locations, migratory behavior and sample sizes among 23 populations for the 576 song sparrows analyzed in this study (see Figure 1)

\begin{tabular}{cll}
\hline Location & Migration status & $\mathrm{n}$ \\
\hline AK & & \\
AT & Sedentary & 30 \\
AD & Sedentary & 30 \\
PN & Sedentary & 21 \\
KO & Partially migratory & 22 \\
CD & Partially migratory & 30 \\
HY & Partially migratory & 18 \\
AA & Partially migratory & 30 \\
& & \\
BC & & \\
QC & Partially migratory \\
MD & Partially migratory & 24 \\
BB & Partially migratory & 30 \\
AK & Partially migratory & 25 \\
RF & Partially migratory & 24 \\
& & 25 \\
SB, CA & & \\
MM & Sedentary & 21 \\
LG & Sedentary & 18 \\
PB & Sedentary & 27 \\
DM & Sedentary & 27 \\
PM & Sedentary & 20 \\
SC & Sedentary & 28 \\
GS & Sedentary & 21 \\
RR & Sedentary & 30 \\
CO & Partially migratory & 22 \\
& &
\end{tabular}

Southern $C A$

WR

SS

Partially migratory

Sedentary

24

Abbreviations: AA, Alexander Archipelago; AD, Adak Island; AK, Alaksen, Westham Island; $A K$, Alaska; AT, Attu Island; BB, Burns Bog; $B C$, British Columbia; $C A$, California; CD, Copper River Delta; CO, Cosumnes River; DM, Dumbarton Marsh; GS, Goodyear Slough; HY, Hyder; KO, Kodiak Island; LG, Los Gatos Creek; MD Mandarte Island; MM, Mark's Marsh; PB, Palo Alto Baylands; PM, Petaluma River Mouth; PN, Alaska Peninsula; QC, Queen Charlotte Islands; RF, Reifel, Westham Island; RR, Rush Ranch Open Space; $S B$, San Francisco Bay; SC, Sonoma Creek; WR, Western Riverside County.

Arcese, 2002, 2003; Patten et al., 2004). Overall, these observations suggest that processes, such as geographic isolation and restricted gene flow, may affect populationlevel diversity and be discernible at larger spatial scales.

Song sparrow populations along the Pacific Coast inhabit two rather different distributional patterns, which for heuristic value we call 'linear' and 'planar'. From western Alaska to British Columbia, most populations are distributed almost linearly, and they are isolated from all other populations except for their nearest coastal neighbors (Figure 1). Populations from coastal British Columbia to California are found on the western edge of the species' continental distribution; but, relative to Alaska populations, they are not isolated from inland populations, being more planar in this distributional dimension (Figure 1). We expected that linear distribution of populations would facilitate isolation and drift, leading these populations to be more structured than planar populations. By combining distribution and migratory behavior, we further categorized song sparrow populations as linear sedentary, linear migratory, planar sedentary, or planar migratory to evaluate the effects of migratory behavior and geographic distribution on population structure. We expected to observe a gradient in population structure, from highly structured linear sedentary populations to undifferentiated planar migratory populations, with other populations falling between these two extremes.

We used nuclear microsatellite loci to test our predictions in 23 populations of song sparrows studied previously by Chan and Arcese (2003); Patten et al. (2004); Pruett and Winker (2005), spanning both the linear and planar distributional and sedentary and migratory behavior patterns represented in the Pacific coastal range of this species (Figure 1, Table 1). Specifically, we asked (1) Is gene flow greater among migratory than sedentary populations? (2) Does genetic structure differ between linear and planar song sparrow populations? And, (3) do linear sedentary populations show a stronger signal of genetic drift and divergence than planar and migratory populations?

\section{Materials and methods}

\section{Sampling and microsatellite data acquisition}

We examined 576 song sparrows from 23 western North American breeding locations (Figure 1, Table 1). Individuals were sampled during the breeding season, making it unlikely that non-breeding transients were included in any samples. Individuals were collected or bled and released, and DNA was extracted following the methods described in Keller et al. (2001); Chan and Arcese (2002, 2003); Patten et al. (2004); Pruett and Winker (2005). Seven microsatellite loci were amplified for all individuals using fluorescent, dye-labeled primers developed for song sparrows (Mme 1, 2, 3, 7, 12; Jeffery et al., 2001) and for two other bird species (Esc $\mu 1$, Hanotte et al., 1994; GF2.35, Petren, 1998). These loci were genotyped as described in Keller et al. (2001); Chan and Arcese (2002, 2003); Patten et al. (2004); Pruett and Winker (2005). As two of the loci are sex linked (Mme3 and Mme7), in analyses we treated females as having missing data for these two loci. Song sparrows with known size fragments (representing scored alleles) were run among studies to ensure that data were concordant. This was carried out by amplifying individuals that had known allele sizes, running these individuals with each run, and scoring alleles based on these known size fragments.

\section{Genetic structure}

Tests for Hardy-Weinberg equilibrium and linkage disequilibrium were performed using ARLEQUIN (ver 2.000, Schneider et al., 2000). Genetic differences between populations (pairwise $F_{\mathrm{ST}}$ ) and whether these values differed significantly from zero $(\alpha=0.05 ; 10000$ permutations) were determined using ARLEQUIN (ver 2.000, Schneider et al., 2000). As $F_{\mathrm{ST}}$ for sex-linked loci may differ from that of autosomal loci (Wang, 1999), we calculated the $F_{\mathrm{ST}}$ separately for autosomal and z-linked loci. These values were then weighted based on the proportion of base pairs found on the sex $(1.5 \%$; 1.5 million base pairs) and autosomal chromosomes in relation to the size of the chicken (Gallus gallus) genome ( $\sim 1$ billion base pairs, http://genomeold.wustl.edu/ projects/chicken/index.php). Values for autosomal and sex-linked loci were combined for an overall pairwise $F_{\mathrm{ST}}$ value. These values were very similar to the unweighted 


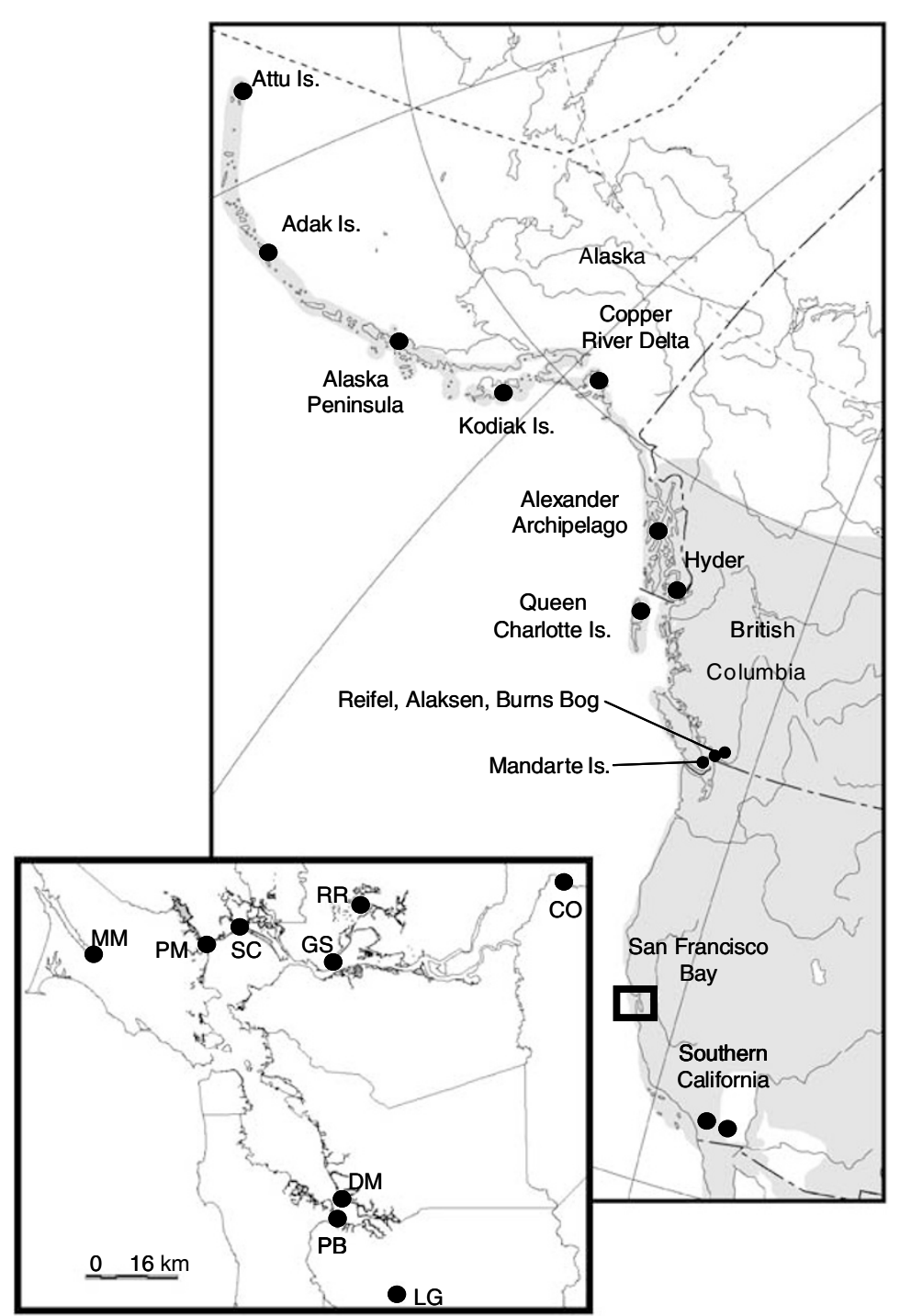
locations. Inset map is of San Francisco Bay, California. Attu Island, Adak Island, Alaska Peninsula, Kodiak Island and Copper River Delta locations are in the species' linear distribution. The remaining locations are part of the species' planar distribution.

$F_{\mathrm{ST}}$ estimates. We constructed a principle coordinates analysis graph using pairwise $F_{\mathrm{ST}}$ estimates (GenAIEx6; Peakall and Smouse, 2006).

\section{Population structure models and assignment tests}

We assessed the relative strengths of drift versus immigration in song sparrow populations using a coalescent-based Markov Chain Monte Carlo method as implemented in the program 2MOD (Ciofi et al., 1999). Two models were evaluated: (1) the gene flow model, which assumes that gene frequencies within populations are caused by a balance between immigration and genetic drift, and (2) the drift model, which assumes that populations diverge solely through genetic drift. The relative likelihood of each model was calculated given the data. Where the gene flow model was judged as most likely, $N m$ (where $N$ is population size and $m$ is immigration rate) was calculated as an estimate of gene flow over time. Where the drift model was chosen, we calculated $t / N$ (where $t$ is the time of divergence; Ciofi et al., 1999). The Markov Chain Monte Carlo search was performed twice for 500000 iterations, with 200000 discarded as burn in. Posterior distributions were checked to ensure convergence.

We used an assignment test to infer movement among populations (Geneclass 2; Piry et al., 2004). When used conservatively, assignment tests have been shown to effectively measure dispersal among populations (Berry et al., 2004). We used the very conservative method outlined by Underwood et al. (2007) to exclude or assign individuals as immigrants using the methods of Rannala and Mountain (1997) and Paetkau et al. (2004). Individuals were excluded from their location of origin when the probability of exclusion was greater than $95 \%$ $(\alpha=0.05)$. Individuals excluded from their population of origin were marginally assigned to another sampled population when $P>0.33$. This probability was chosen based on the lowest mean Bayesian probability for the populations examined and thus represents a very conservative method of identifying immigrants. Individuals not assigned to any population with a 
probability of $P>0.33$ were assumed to be from an unsampled population, because we did not sample the entire distribution of song sparrows. We also attempted to use the program BayesAss (Wilson and Rannala, 2003) to infer gene flow among populations. However, our analyses failed to yield reliable results (see Faubet et al., 2007).

\section{Matrix correlations}

Associations between $F_{\mathrm{ST}} /\left(1-F_{\mathrm{ST}}\right)$ and log-transformed geographic distance and between these two variables controlling for the effect of angular direction (logtransformed bearing) were assessed using simple and partial Mantel tests. We constructed matrices of greatcircle distances (http://mathworld.wolfram.com/GreatCircle.html) in kilometer and rhumb line bearings (straight-line routes that cross all of the meridians at the same angle based on a Mercator projection) between collection locations. We performed two comparisons for each association (six comparisons total): the entire matrix, the five linear populations (Attu Island to Copper River Delta; Figure 1), and the remaining 18 planar populations (Figure 1). All Mantel tests were performed using the program zt (Bonnet and Van de Peer, 2002), with significance of correlations assessed with 10000 random permutations of the dependent matrix.

\section{Results}

\section{Genetic structure}

Tests for Hardy-Weinberg equilibrium showed that two loci (Mme1 from Attu Island and Mme2 from Kodiak island, Alexander Archipelago, Alaksen and Reifel) were deficient in heterozygotes after adjustments for multiple comparisons. All loci were in linkage equilibrium.

Most pairwise $F_{\mathrm{ST}}$ estimates (Table 2) were significantly different from zero after Bonferroni correction $(\alpha=0.0002,253$ tests). The highest pairwise estimates of $F_{\mathrm{ST}}$ were found between all locations and Attu (0.14-0.40) and Adak (0.09-0.26) islands. Comparisons among some populations in British Columbia and most populations in California did not differ significantly from zero (Table 2). A principle coordinates analysis plot showed that most populations with planar distributions clustered together, with the exception of two in San Francisco Bay (Figures 1 and 2), Palo Alto Baylands and Dumbarton

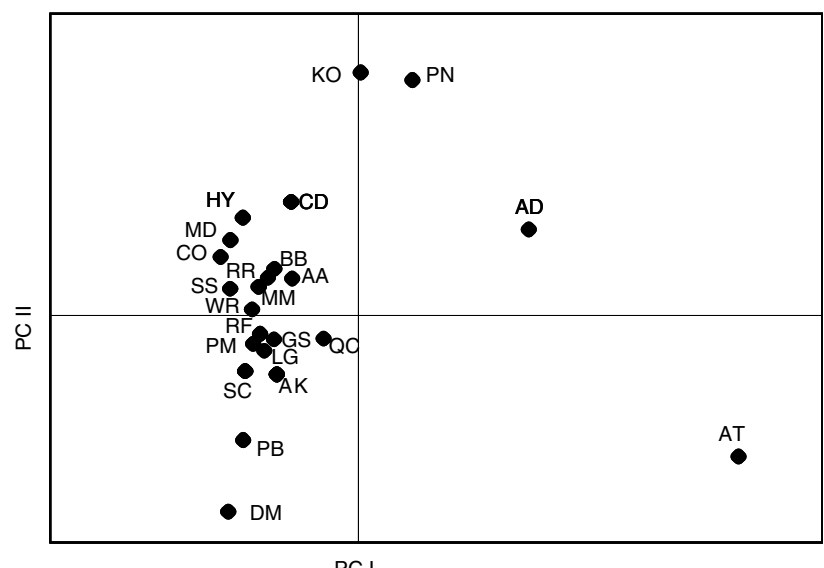

Figure 2 Principal coordinates analysis calculated using pairwise $F_{\mathrm{ST}}$ estimates between sites using the program GenAIEx (Peakall and Smouse, 2006). The first two axes explain $92.3 \%$ of variation.

Table 2 Pairwise estimates between song sparrow populations of genetic differentiation $\left(F_{S T}\right)$

\begin{tabular}{|c|c|c|c|c|c|c|c|c|c|c|c|c|c|c|c|c|c|c|c|c|c|c|}
\hline & $A T$ & $A D$ & $P N$ & KO & $C D$ & $H Y$ & $A A$ & $Q C$ & $M D$ & $B B$ & $A K$ & $R F$ & $M M$ & $L G$ & $P B$ & $D M$ & $P M$ & $S C$ & GS & $R R$ & $\mathrm{CO}$ & $W R$ \\
\hline $\mathrm{AD}$ & 0.14 & - & & & & & & & & & & & & & & & & & & & & \\
\hline $\mathrm{PN}$ & 0.29 & 0.09 & - & & & & & & & & & & & & & & & & & & & \\
\hline $\mathrm{KO}$ & 0.37 & 0.18 & 0.09 & - & & & & & & & & & & & & & & & & & & \\
\hline CD & 0.34 & 0.21 & 0.17 & 0.09 & - & & & & & & & & & & & & & & & & & \\
\hline HY & 0.37 & 0.21 & 0.17 & 0.11 & 0.05 & - & & & & & & & & & & & & & & & & \\
\hline AA & 0.32 & 0.20 & 0.16 & 0.11 & 0.05 & 0.03 & - & & & & & & & & & & & & & & & \\
\hline $\mathrm{QC}$ & 0.34 & 0.21 & 0.18 & 0.11 & 0.07 & 0.04 & 0.03 & - & & & & & & & & & & & & & & \\
\hline MD & 0.37 & 0.25 & 0.20 & 0.10 & 0.12 & 0.10 & 0.08 & 0.09 & - & & & & & & & & & & & & & \\
\hline BB & 0.38 & 0.22 & 0.17 & 0.11 & 0.10 & 0.04 & 0.01 & 0.04 & 0.05 & - & & & & & & & & & & & & \\
\hline AK & 0.37 & 0.23 & 0.20 & 0.14 & 0.10 & 0.06 & 0.03 & 0.06 & 0.07 & 0.00 & - & & & & & & & & & & & \\
\hline RF & 0.38 & 0.24 & 0.19 & 0.14 & 0.09 & 0.06 & 0.03 & 0.06 & 0.06 & 0.02 & 0.01 & - & & & & & & & & & & \\
\hline MM & 0.38 & 0.22 & 0.15 & 0.10 & 0.10 & 0.06 & 0.06 & 0.09 & 0.11 & 0.04 & 0.04 & 0.04 & - & & & & & & & & & \\
\hline LG & 0.39 & 0.23 & 0.18 & 0.13 & 0.09 & 0.07 & 0.05 & 0.08 & 0.09 & 0.04 & 0.04 & 0.04 & 0.02 & - & & & & & & & & \\
\hline PB & 0.39 & 0.24 & 0.20 & 0.16 & 0.11 & 0.07 & 0.04 & 0.09 & 0.13 & 0.03 & 0.04 & 0.03 & 0.05 & 0.03 & - & & & & & & & \\
\hline DM & 0.40 & 0.26 & 0.23 & 0.19 & 0.12 & 0.09 & 0.06 & 0.10 & 0.15 & 0.07 & 0.06 & 0.04 & 0.07 & 0.04 & 0.02 & - & & & & & & \\
\hline PM & 0.35 & 0.20 & 0.14 & 0.11 & 0.08 & 0.05 & 0.04 & 0.07 & 0.08 & 0.03 & 0.02 & 0.02 & 0.01 & 0.01 & 0.04 & 0.04 & - & & & & & \\
\hline SC & 0.35 & 0.22 & 0.16 & 0.10 & 0.09 & 0.06 & 0.04 & 0.07 & 0.09 & 0.02 & 0.02 & 0.02 & 0.01 & 0.00 & 0.02 & 0.03 & 0.00 & - & & & & \\
\hline GS & 0.36 & 0.22 & 0.17 & 0.16 & 0.09 & 0.07 & 0.04 & 0.07 & 0.09 & 0.02 & 0.02 & 0.01 & 0.02 & 0.01 & 0.03 & 0.04 & 0.00 & 0.00 & - & & & \\
\hline RR & 0.36 & 0.21 & 0.16 & 0.11 & 0.10 & 0.06 & 0.04 & 0.08 & 0.08 & 0.02 & 0.02 & 0.02 & 0.02 & 0.00 & 0.03 & 0.05 & 0.00 & 0.00 & 0.00 & - & & \\
\hline $\mathrm{CO}$ & 0.38 & 0.22 & 0.15 & 0.11 & 0.10 & 0.05 & 0.05 & 0.08 & 0.09 & 0.03 & 0.04 & 0.03 & 0.02 & 0.01 & 0.04 & 0.05 & 0.00 & 0.01 & 0.03 & 0.00 & - & \\
\hline WR & 0.36 & 0.21 & 0.16 & 0.11 & 0.10 & 0.06 & 0.05 & 0.08 & 0.08 & 0.02 & 0.02 & 0.02 & 0.01 & 0.01 & 0.03 & 0.04 & 0.01 & 0.01 & 0.01 & 0.01 & 0.03 & - \\
\hline SS & 0.39 & 0.24 & 0.17 & 0.13 & 0.11 & 0.07 & 0.07 & 0.10 & 0.11 & 0.05 & 0.05 & 0.04 & 0.02 & 0.03 & 0.05 & 0.05 & 0.02 & 0.02 & 0.03 & 0.03 & 0.02 & 0.02 \\
\hline
\end{tabular}

Abbreviations: AA, Alexander Archipelago; AD, Adak Island; AK, Alaksen, Westham Island; AT, Attu Island; BB, Burns Bog; CD, Copper River Delta; CO, Cosumnes River; DM, Dumbarton Marsh; GS, Goodyear Slough; HY, Hyder; KO, Kodiak Island; LG, Los Gatos Creek; MD, Mandarte Island; MM, Mark's Marsh; PB, Palo Alto Baylands; PM, Petaluma River Mouth; PN, Alaska Peninsula; QC, Queen Charlotte Islands; RF, Reifel, Westham Island; RR, Rush Ranch Open Space; SC, Sonoma Creek; WR, Western Riverside County.

$F_{S T}$ estimates in italics are not significantly different from zero after Bonferroni correction $(P=0.0002,253$ tests). Seventy-nine percent (201) of pairwise comparisons exhibited significant genetic differentiation after Bonferroni correction. 
Marsh. Populations in the linear distribution were the most genetically differentiated (Figures 1 and 2).

\section{Population structure models and assignment tests}

The genetic structure of all song sparrow populations is best explained by the gene flow model $(P=1.00)$. The relative effects of gene flow and genetic drift were evaluated using $F$ (the probability of identical alleles by descent) and $M$ (the number of migrants per generation; Ciofi et al., 1999). Low levels of immigration over time relative to drift were inferred in the linear populations (Table 3), with Attu Island showing the strongest signal of drift $(F=0.65,90 \%$ highest posterior density range: $0.52-0.69 ; M=0.14)$. In contrast, high levels of immigration relative to drift were found in most of the planar populations $(F=0.02-0.18 ; M=1.16-12.9)$. Using information available from long-term studies of song sparrows (Arcese et al., 2002), we used the formula by Sæther et al. (2005) to estimate a generation time of 2.56 years for the species. On the basis of this estimate, one migrant per 18.6 years has reached Attu Island and less than one migrant per year has reached the other linear populations (Table 3). In contrast, planar populations were estimated to have several immigrants annually into both migratory and sedentary populations (Table 3).

Forty-seven of 576 birds $(8.16 \%)$ were excluded as having originated in the location where they were sampled with a probability of $\geqslant 95 \%$ (Table 3 ). Of these 47 birds, 17 were assigned to another location and 15 of those 17 assigned best to partially migratory populations. Thirty individuals were not assignable with a high probability to any site (Table 3 ). The percentage of individuals excluded from their location of origin ranged between 3 and 22\% (Table 3). Similar numbers of individuals from migratory $(N=16)$ and sedentary $(N=14)$ populations did not assign strongly to any population. Individuals from migratory populations appeared to move greater distances when dispersing to another location, with average distances moved from migratory to migratory $(N=10 ; 1409 \mathrm{~km} \pm 369)$ and migratory to sedentary $(N=5 ; 772 \mathrm{~km} \pm 216)$ being much larger than from sedentary to sedentary $(N=2$; $65 \mathrm{~km} \pm 39)$ and from sedentary into migratory populations $(N=0)$.

\section{Matrix correlations}

We found several strong correlations between genetic and geographic matrices including a significant correlation between $F_{\mathrm{ST}}$ and geographic distance $(r=0.538$ $P=0.0001$ ), even after controlling for the effect of angular direction in the entire dataset $(r=0.502 ; P=0.0001)$. When submatrices were examined, both distributional patterns showed a signal of isolation by distance (linear $r=0.809, P=0.0083$; planar $r=0.500, P=0.0001$ ), even after accounting for a possible interaction between distance and angle of direction (linear $r=0.825$, $P=0.017$; planar $r=0.505, P=0.0001)$. However, there

Table $32 \mathrm{MOD}$ and GENECLASS test results for western song sparrow populations

\begin{tabular}{|c|c|c|c|c|c|c|c|c|}
\hline \multirow[t]{2}{*}{ Location } & \multirow[t]{2}{*}{$\mathrm{n}$} & \multicolumn{3}{|c|}{$2 M O D$} & \multicolumn{4}{|c|}{ GENECLASS } \\
\hline & & $F(90 \%$ HPD $)$ & $M$ & Years/migrant & $M B P$ & Unassigned & Assigned & Likely origin \\
\hline $\mathrm{AT}$ & 30 & $0.65(0.52-0.69)$ & 0.14 & 18.6 & 0.70 & 1 & 0 & - \\
\hline $\mathrm{AD}$ & 30 & $0.50(0.39-0.52)$ & 0.25 & 10.1 & 0.63 & 2 & 0 & - \\
\hline PN & 21 & $0.32(0.26-0.34)$ & 0.53 & 4.87 & 0.59 & 3 & 2 & $\mathrm{HY}, \mathrm{CD}$ \\
\hline $\mathrm{KO}$ & 22 & $0.21(0.21-0.29)$ & 0.97 & 1.52 & 0.59 & 3 & 1 & WR \\
\hline $\mathrm{CD}$ & 30 & $0.12(0.09-0.12)$ & 1.88 & 1.36 & 0.52 & 3 & 1 & BB \\
\hline HY & 18 & $0.07(0.06-0.09)$ & 3.10 & 0.83 & 0.36 & 2 & 2 & $\mathrm{MD}, \mathrm{CO}$ \\
\hline AA & 30 & $0.05(0.04-0.07)$ & 5.05 & 0.51 & 0.45 & 0 & 0 & - \\
\hline QC & 24 & $0.10(0.10-0.15)$ & 2.32 & 1.10 & 0.49 & 4 & 0 & - \\
\hline MD & 30 & $0.18(0.15-0.25)$ & 1.16 & 2.21 & 0.53 & 3 & 2 & $\mathrm{BB}, \mathrm{WR}$ \\
\hline $\mathrm{BB}$ & 24 & $0.05(0.04-0.09)$ & 4.67 & 0.55 & 0.62 & 3 & 1 & RF \\
\hline AK & 24 & $0.06(0.05-0.08)$ & 3.60 & 0.71 & 0.53 & 2 & 1 & $\mathrm{RF}$ \\
\hline $\mathrm{RF}$ & 25 & $0.05(0.05-0.08)$ & 4.31 & 0.59 & 0.57 & 1 & 0 & - \\
\hline MM & 21 & $0.04(0.04-0.07)$ & 5.52 & 0.46 & 0.47 & 2 & 1 & $\mathrm{BB}$ \\
\hline LG & 18 & $0.02(0.02-0.04)$ & 11.2 & 0.23 & 0.33 & 4 & 1 & PM \\
\hline PB & 27 & $0.06(0.05-0.07)$ & 4.04 & 0.63 & 0.54 & 1 & 0 & - \\
\hline DM & 27 & $0.04(0.04-0.10)$ & 5.34 & 0.48 & 0.56 & 1 & 0 & - \\
\hline PM & 20 & $0.02(0.02-0.04)$ & 11.3 & 0.23 & 0.49 & 1 & 0 & - \\
\hline SC & 28 & $0.02(0.02-0.03)$ & 12.9 & 0.20 & 0.49 & 4 & 3 & AK, GS, WR \\
\hline GS & 21 & $0.03(0.02-0.04)$ & 8.55 & 0.30 & 0.41 & 3 & 2 & $\mathrm{CO}, \mathrm{WR}$ \\
\hline RR & 30 & $0.03(0.02-0.04)$ & 7.03 & 0.36 & 0.61 & 0 & 0 & - \\
\hline $\mathrm{CO}$ & 22 & $0.02(0.01-0.04)$ & 10.7 & 0.24 & 0.41 & 1 & 0 & - \\
\hline WR & 24 & $0.02(0.02-0.04)$ & 11.8 & 0.22 & 0.38 & 2 & 0 & - \\
\hline SS & 29 & $0.04(0.04-0.07)$ & 5.68 & 0.45 & 0.58 & 1 & 0 & - \\
\hline
\end{tabular}

Abbreviations: AA, Alexander Archipelago; AD, Adak Island; AK, Alaksen, Westham Island; AT, Attu Island; BB, Burns Bog; CD, Copper River Delta; CO, Cosumnes River; DM, Dumbarton Marsh; GS, Goodyear Slough; HPD, highest posterior density; HY, Hyder; KO, Kodiak Island; LG, Los Gatos Creek; MBP, mean Bayesian probability; MD, Mandarte Island; MM, Mark's Marsh; PB, Palo Alto Baylands; PM, Petaluma River Mouth; PN, Alaska Peninsula; QC, Queen Charlotte Islands; RF, Reifel, Westham Island; RR, Rush Ranch Open Space; SC, Sonoma Creek; WR, Western Riverside County.

$2 \mathrm{MOD}$ results are based on the gene flow model with $F$ being the probability that two genes share a common ancestor within a population and $M$ being the number of migrants per generation. Years per migrant (years/migrant) are based on the estimated generation time of song sparrows of 2.56 years. GENECLASS results show the number of individuals excluded from their population of origin (unassigned), when there was less than a 0.05 chance that their genotype occurs at that site. Assigned individuals have a greater than 0.33 likelihood of being the source for an immigrant. 


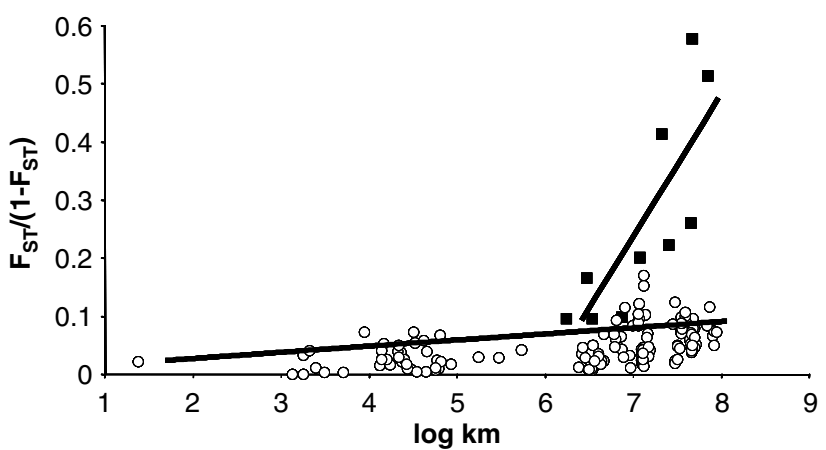

Figure 3 Plot of genetic divergence $\left(F_{\mathrm{ST}} / 1-F_{\mathrm{ST}}\right)$ and log-transformed geographic distance in kilometer for linear (black squares) and planar (white circles) populations.

was a much steeper association between $F_{\mathrm{ST}}$ and geographic distance for the linear populations (Figure 3).

\section{Discussion}

\section{Effects of migration on genetic structure}

Migratory behavior appears to facilitate dispersal in Pacific coast song sparrow populations and as suggested by Paradis et al. (1998) may act to increase gene flow and reduce genetic structure among populations. In Pacific coast song sparrows, $88 \%$ of unassigned birds had likely dispersed from a partially migratory population (assigned strongly to another site), and this dispersal was potentially over large distances ( $>500 \mathrm{~km}$; Figure 1, Table 3). Long-distance movement of over $1000 \mathrm{~km}$ has been documented in song sparrows based on banding recoveries (Davis and Arcese, 1999). Theory suggests that long-distance dispersal events should reduce population genetic structure (Ibrahim et al., 1996). But in song sparrows, movement among geographically distant populations does not appear to have counteracted the effects of genetic drift, especially in populations that are geographically isolated. For example, the Kodiak Island population had an individual that assigned with high likelihood to southern California (WR). However, song sparrows from Kodiak Island differ genetically from those sampled in California and show a strong signal of genetic drift, less than one immigrant per generation. If outbreeding depression occurs among hybrids from distant populations, natural selection may also influence the genetically effective rate of migration and reduce its influence on population differentiation (Marr et al., 2002). Another possibility is that the misassigned individual from Kodiak Island dispersed from an unsampled interior location that was genetically very similar to the southern California population. Given that genetic structuring is evident at microgeographic scales (Figure 2), the likelihood of a location several hundred kilometers away from southern California exhibiting a similar genetic signature as the WR population seems remote. Regardless, the nearest unsampled populations are greater than $500 \mathrm{~km}$ from Kodiak Island (Figure 1) and are migratory. Thus, long-distance dispersal (in this instance) is very likely from a migratory population.

Our results also suggest that most individuals from sedentary populations of song sparrows remain philopatric to their natal population, or when disperse they move relatively short distances to other sedentary populations (based on assignment tests; Table 3). Apparent immigrants coming from a sedentary location dispersed on average $65 \mathrm{~km}$. In contrast, short-distance dispersal might be linked to ongoing gene flow in some San Francisco Bay populations that cannot be distinguished genetically. Other sedentary populations appeared to be currently isolated with no individuals excluded by assignment test but nevertheless showed fairly high numbers of immigrants per generation (more than four individuals per generation) and a weak signal of genetic drift (Table 3), perhaps as a consequence of high historic gene flow but current isolation. A lack of current gene flow appears sufficient to have isolated song sparrow populations in the Palo Alto Baylands and at Dumbarton Marsh, contributing to their divergence from other populations of song sparrows in San Francisco Bay.

\section{Effects of distributional pattern on population structure} Pacific coastal populations of song sparrows are distributed relative to neighboring populations in two different ways, which we have heuristically termed linear and planar on a macrogeographic scale (Figure 1). The genetic structures of populations associated with each distributional pattern were markedly dissimilar. Linearly distributed populations displayed more genetic structure and stronger signal of genetic drift than populations occurring along the continental planar distribution. There was modest genetic structure among populations occurring along the edge of the planar distributional pattern, with southeast Alaska and British Columbia locations having significantly different $F_{\mathrm{ST}}$ values from California locations. However, at finer scales, populations within British Columbia or California, were not strongly geographically structured except for two locations in San Francisco Bay (Dumbarton Marsh and Palo Alto Baylands). The marked differentiation of these two populations was noted previously by Chan and Arcese $(2002,2003)$ and reflects isolation due to adaptive differences in salinity tolerance or cryptic geographic barriers. Whatever the reason, these two populations clearly do not fit the patterns expected with the larger-scale condition among other planar populations where there are no strong geographic isolating barriers to gene flow.

The differences between linear and planar populations were also apparent in the matrix correlations (Figure 3): genetics and geography were correlated significantly across the entire dataset. This association appeared to be primarily due to the strong signal of isolation by distance among linear populations. Although there was genetic structuring within the planar populations, it was not as strongly correlated with geographic distance. Whether or not populations were oriented in a north-south or eastwest direction was not correlated with the genetic divergence among populations. Pruett and Winker (2005) found a sequential loss in diversity and an increase in differentiation among the linear populations that was likely caused by the initial founding of Alaska by song sparrows. However, the maintenance of genetic relationships among these populations is most likely the result of restricted gene flow caused by their linear distribution. Although our results may be confounded to some degree by differences in life-history strategy (that 
is, sedentariness versus partial seasonal migration), there appear to be pronounced genetic effects to being distributed in a one-dimensional (linear) versus a twodimensional (planar) macrogeographic pattern.

\section{Synergy of geography and behavior}

By sampling across geographically (linear versus planar) and behaviorally (sedentary versus seasonally migratory) varying populations, we can evaluate whether there is a synergistic effect of being linearly distributed and sedentary or planarly distributed and migratory. These complementarily coupled patterns would theoretically represent synergistic extremes in which linear sedentary populations should be strongly differentiated from other populations and planar-migratory populations should be the least differentiated because of differences in gene flow in these coupled patterns. Linear populations do fit this expected pattern. Linear sedentary populations (Aleutian Island and Alaska Peninsula) showed a strong genetic signal of drift and differentiation, and thus it seems likely that geography and behavior are synergistically maintaining differentiation in these populations. Kodiak Island and Copper River Delta song sparrows are linear migratory and have a moderate signal of differentiation with limited gene flow. Thus, migratory behavior does seem to facilitate gene flow to some extent in these linear populations.

Among planar sedentary San Francisco Bay populations, Dumbarton Marsh and Palo Alto Baylands strongly differed from all other populations. Thus, sedentariness does appear to have an effect on the genetic structuring of these populations. However, other San Francisco Bay song sparrows showed little differentiation among themselves and when contrasted with planar migratory populations. In addition, planar sedentary birds from the Salton Sea were similar to other planar populations. We found that planar migratory populations in British Columbia and southern California also were not divergent from other populations. These findings suggest that a planar distribution is more important than migratory behavior in structuring song sparrow populations. However, an equally plausible explanation is that historic signals of high gene flow (high number of migrants per generation in the 2MOD analysis; Table 3) are obscuring contemporary effects of limited gene flow.

Teasing apart the roles of historic and contemporary processes is difficult. However, it is apparent that both processes have played and continue to play a strong role in the genetic structure occurring today in Pacific coastal song sparrows. Limited dispersal among populations, with much of this dispersal apparently occurring over large geographic distances, appears to have little effect on homogenizing the genetics of geographically distant populations. This limited movement should, over time, lead to higher differentiation-and potentially to speciation-especially in isolated, linearly distributed populations.

\section{Acknowledgements}

This project was supported by the University of Alaska Museum, Universities of Wisconsin and British Columbia, the American Museum of Natural History, the National Geographic Society, the U.S. Department of
Agriculture (USDA-ARS), the US National Science Foundation (DEB-9981915, IBN-9458122), Swiss National Science Foundation, Natural Sciences and Engineering Research Council of Canada, Center for Global Change and Arctic System Research, Hildegard and Werner Hesse and an anonymous donor.

\section{References}

Arcese P (1989). Intrasexual competition, mating system and natal dispersal in song sparrows. Anim Behav 38: 958-979.

Arcese P, Sogge MK, Marr AB, Patten MA (2002). Song sparrow (Melospiza melodia). in: Poole A, Gill F (eds). The Birds of North America. Birds of North America Inc: Philadelphia, Pennsylvania. No. 704.

Arguedas N, Parker PG (2000). Seasonal migration and genetic population structure in house wrens. Condor 102: 517-528.

Berry O, Tocher MD, Sarre SD (2004). Can assignment tests measure dispersal? Mol Ecol 13: 551-561.

Bonnet E, Van de Peer Y (2002). zt: a software tool for simple and partial Mantel tests. J Stat Softw 7: 1-12.

Chan Y, Arcese P (2002). Subspecific differentiation and conservation of song sparrows (Melospiza melodia) in the San Francisco Bay region inferred by microsatellite loci analysis. Auk 119: 641-657.

Chan Y, Arcese P (2003). Morphological and microsatellite differentiation in Melospiza melodia (Aves) at a microgeographic scale. J Evol Biol 16: 1-9.

Ciofi C, Beaumont MA, Swingland IR, Bruford MW (1999). Genetic divergence and units for conservation in the Komodo dragon Varanus komodoensis. Proc Biol Sci 266: 2269-2274.

Coyne JA, Orr HA (2004). Speciation. Sinauer: Sunderland, Massachusetts.

Davis A, Arcese P (1999). An examination of migration in song sparrows using banding recovery data. N Am Bird-band 24: 124-128.

Faubet P, Waples RS, Gaggiotti OE (2007). Evaluating the performance of a multilocus Bayesian method for the estimation of migration rates. Mol Ecol 16: 1149-1166.

Fry AJ, Zink RM (1998). Geographic analysis of nucleotide diversity and song sparrow (Aves: Emberizidae) population history. Mol Ecol 7: 1303-1313.

Hanotte O, Zanon C, Pugh A, Grieg C, Dixon A, Burke T (1994). Isolation and characterization of microsatellite loci in a passerine bird: the reed bunting Emberiza schoeniclus. Mol Ecol 3: $529-530$

Hare MP, Shields GF (1992). Mitochondrial-DNA variation in the polytypic Alaskan song sparrow. Auk 109: 126-132.

Ibrahim KM, Nichols RA, Hewitt GM (1996). Spatial patterns of genetic variation generated by different forms of dispersal during range expansion. Heredity 77: 282-291.

Jeffery KJ, Keller LF, Arcese P, Bruford MW (2001). The development of microsatellite loci in the song sparrow, Melospiza melodia, and genotyping errors associated with good quality DNA. Mol Ecol Notes 1: 11-13.

Keller LF, Jeffery KJ, Arcese P, Bruford MW (2001). Immigration and the ephemerality of a natural population bottleneck: evidence from molecular markers. Proc Biol Sci 268: 1387-1394.

Marr AB, Keller LJ, Arcese P (2002). Heterosis and outbreeding depression in descendents of natural immigrants to an inbred population of song sparrows (Melospiza melodia). Evolution 56: 131-142.

Paetkau D, Slade R, Burdens M, Estoup A (2004). Genetic assignment methods for the direct, real-time estimation of migration rate: a simulation-based exploration of accuracy and power. Mol Ecol 13: 55-65. 
Paradis E, Baillie SR, Sutherland WJ, Gregory RD (1998) Patterns of natal and breeding dispersal in birds. J Anim Ecol 67: 518-536.

Patten MA, Rotenberry JT, Zuk M (2004). Habitat selection, acoustic adaptations, and the evolution of reproductive isolation. Evolution 58: 2144-2155.

Peakall R, Smouse PE (2006). GenAIEx 6: Genetic Analysis in Excel. Population genetic software for teaching and research. Mol Ecol Notes 6: 288-295.

Petren K (1998). Microsatellite primers from Geospiza fortis and cross species amplification in Darwin's finches. Mol Ecol 7: 1782-1784.

Piry S, Alapetite A, Cornuet J-M, Paetkau D, Baudouin L, Estoup A (2004). GeneClass2: a software for genetic assignment and first-generation migrant detection. J Hered 95: 536-539.

Pruett CL, Winker K (2005). Northwestern song sparrow populations show genetic effects of sequential colonization. Mol Ecol 14: 1421-1434.

Rannala B, Mountain JL (1997). Detecting immigration by using multilocus genotypes. Proc Natl Acad Sci USA 94: 9197-9201.
Sæther B-E, Lande R, Engen S, Weimerskirch H, Lillegard M, Altwegg $R$ et al. (2005). Generation time and temporal scaling of bird population dynamics. Nature 436: 99-102.

Schneider S, Roessli D, Excoffier L (2000). Arlequin ver. 2.000: A Software for Population Genetic Data Analysis. Genetics and Biometry Laboratory: University of Geneva, Switzerland.

Underwood JN, Smith LD, Van Oppen MJH, Gilmour JP (2007). Multiple scales of genetic connectivity in the brooding coral on isolated reefs following catastrophic bleaching. Mol Ecol 16: 771-784.

Wang J (1999). Effective size and F-statistics of subdivided populations for sex-linked loci. Theor Popul Biol 55: 176-188.

Wilson GA, Rannala B (2003). Bayesian inference of recent migration rates using multilocus genotypes. Genetics 163: 1177-1191.

Wilson AG, Arcese P (2008). Factors influencing natal dispersal in an avian island metapopulation. J Avian Biol 39: (in press).

Zink RM, Dittmann DL (1993). Gene flow, refugia, and evolution of geographic variation in the song sparrow (Melospiza melodia). Evolution 47: 717-729. 